Re-submitted for J Neuro-Oncology 091213

\title{
Metronomic treatment with irinotecan (CPT-11) against malignant glioma xenografts inhibits angiogenesis and tumor growth
}

Shingo Takano, Hiroshi Kamiyama, Ryota Mashiko, Satoru Osuka, Eiichi Ishikawa, Akira Matsumura

Department of Neurosurgery, Institute of Clinical Medicine, Graduate School of Comprehensive Human Sciences, University of Tsukuba

1-1-1 Tennoudai, Tsukuba city, Ibaraki 305-8575, JAPAN

\begin{abstract}
Purpose: Irinotecan (CPT-11) has shown emerging promise in the treatment of malignant gliomas. The mechanism of action has been considered that irinotecan sensitizes glioma cells to the cytotoxic actions of radiation therapy and alkylating agents. However, clinical trials using weekly or dosing of CPT-11 every 3 weeks have demonstrated imaging responses in only $10-15 \%$ of patients. In this study, we evaluated another mechanism of action, angiosuppression, of CPT-11 for ACNU-resistant gliomas using a metronomic administration schedule.

Methods: Two different types of treatment, 1) conventional and 2) metronomic were applied for the subcutaneous U87 model.

Results: We found that metronomic administration of CPT-11 significantly inhibited malignant glioma growth by inhibiting angiogenesis; this treatment protocol decreased the number of tumor vessels and the area of hypoxic lesions and decreased the expression of VEGF and HIF-1 $\alpha$, the most important angiogenic factors in gliomas. Metronomic treatment was superior compared to conventional treatment with regard to the severe systemic side effect of body weight loss. The
\end{abstract}


growth inhibitory effect was very similar at both the low and high doses of CPT-11.

Conclusions: These angiosuppressive effects of CPT-11 show promise for another usage of CPT-11 in metronomic and scheduled angiosuppressive chemotherapy with low dose and long-term administration for malignant gliomas without systemic side effects.

Keywords Irinotecan, Angiosuppression, Vascular endothelial growth factor, Malignant glioma, ACNU, Xenografts, Metronomic treatment

Abbreviations $\mathrm{IC}_{50}$ : The concentration of drug required to inhibit cell growth by $50 \%$ compared to non-drug-treated controls, MGMT: $\mathrm{O}^{6}$-methylguanine-DNA methyltransferase, VEGF: Vascular endothelial growth factor 


\section{Introduction}

Malignant gliomas have remained a major cause of death in adults and children despite therapeutic strategies that include maximal surgical resection followed by radiochemotherapy. Although there is great promise for future strategies involving anti-angiogenic agents, chemotherapy, or vaccines, it will likely be years before we see true therapeutic benefits from these newer modalities. Other than the nitrosoureas (BCNU, ACNU, CCNU) and temozolomide, no agents have consistently demonstrated clinically meaningful benefits for patients with gliomas.

Irinotecan has shown emerging promise in the treatment of malignant gliomas following many laboratory studies and phase I and II clinical trials [1, 2]. Currently, a phase II trial of BCNU and CPT-11 in adults with newly diagnosed or recurrent malignant gliomas and phase I and II trials of CPT-11 and temozolomide are ongoing. CPT-11 may hold importance for neuro-oncology for a number of reasons. CPT-11, topoisomerase I inhibitors, utilize a different mechanism of action compared with other glioma therapies, particularly the alkylating agents. Preclinical and clinical data indicate that irinotecan may sensitize glioma cells to the cytotoxic actions of radiation therapy and alkylating agents. In addition, CPT-11 is among a small group of cytotoxic agents that readily cross the blood-brain barrier. However, clinical trials using weekly or dosing of irinotecan every 3 weeks have demonstrated imaging responses in only $10-15 \%$ of patients. Recent data for CPT-11 and bevacizumab combination therapy suggests that there is a synergy between irinotecan and ant-VEGF therapies, with acceptable toxicity [3]. We have demonstrated the antiangiogenic action of CPT-11 in vitro [4], including the anti-VEGF and anti-HIF (hypoxia inducible factor) effects of CPT-11 itself. Moreover, metronomic dosing regimens- either continuous infusion or frequent administration without extended rest periods- could have targeting proliferating endothelial cells in the tumor [5]. In this study, we evaluated another mechanism of action, angiosuppression, of CPT-11 using a 
metronomic schedule in vivo in the glioma model.

\section{Materials and methods}

\section{Establishment of the ACNU-resistant clone: U87AR}

Because U87-MG has been known to express faint $\mathrm{O}^{6}$-methylguanine-DNA methyltransferase (MGMT) mRNA which is involved in the drug resistance of tumor cells to ACNU (Mineura et al., 1996), we chose U87 MG for the establishment of the ACNU-resistant clone. U87-MG was obtained from the American Type Culture Collection (Rockville, MD). Cells were maintained in MEM supplemented with $10 \%$ FCS in a humidified atmosphere $5 \% \mathrm{CO}_{2}$ at $37^{\circ} \mathrm{C}$. U87 MG was cultured in MEM supplemented with 10\% FCS and $10 \mu \mathrm{M}$ ACNU in a humidified atmosphere containing 5\% $\mathrm{CO}_{2}$ at $37^{\circ} \mathrm{C}$, and the medium was changed 2 times per week for 5 weeks . Total RNA was extracted from glioma cells using the RNeasy Mini Kit (Qiagen GmbH, Germany) and we performed RT-PCR using the GeneAmp ${ }^{\text {TM }}$ RNA PCR Kit (Perkin-Elmer Cetus, Norwalk, CT), as described previously [6]. Briefly, $1 \mu \mathrm{g}$ of total RNA was reverse transcribed by MuLV reverse transcriptase in the presence of random hexamers, followed by the indicated number of cycles of PCR reaction $\left(95^{\circ} \mathrm{C}\right.$ for $1 \mathrm{~min}, 55^{\circ} \mathrm{C}$ for $1 \mathrm{~min}$, and $72^{\circ} \mathrm{C}$ for $1 \mathrm{~min}$ ) in the presence of $2 \mu \mathrm{M}$ MGMT specific primers (35 cycles), or the $ß$-actin specific primers (16 cycles) as a control. The MGMT primers included the reverse primer (5'-ATCCGATGCAGTGTTACACG -3‘ within exon 5) and the forward primer (5’-ACCGTTTGCGACTTGGTACT-3‘ within exon 1) [7]. The ß-actin primers included the reverse primer (5'-GGAGTTGAAGGTAGTTTCGTG-3‘) spanning bases 2429-2409 and the forward primer (5’-CGGGAAATCGTGCGTGACAT-3`) spanning bases 2107-2126 [8]. The predicted sizes of the amplified MGMT and ß-actin DNA products were 923 bp and 214 bp, respectively. The quantification of these RT-PCR products levels was performed on a computer using the public domain NIH Image program (developed at the U.S. National Institute of Health). After repeated 
exposure to ACNU, we obtained U87-MG cells that exhibited high expression of MGMT mRNA, which was referred to as U87AR.

U87-MG and U87AR glioma cell proliferation with chemotherapeutic agents (ACNU and SN38; active metabolite of CPT-11) was assessed using the MTT assays described previously [9]. ACNU was provided by Sankyo company (Tokyo). SN38 was provided by Daiichi Pharmaceutical Company (Tokyo). MGMT expression was markedly enhanced in U87AR compared to U87MG (data not shown). The calculated IC 50 with ACNU was $80 \mu \mathrm{M}$ for U87-MG and $988 \mu \mathrm{M}$ for U87AR. In contrast, the $\mathrm{IC}_{50}$ with $\mathrm{SN} 38$ was $70 \mathrm{nM}$ for U87-MG and $20 \mathrm{nM}$ for U87AR. U87AR is ten times more resistant to ACNU compared with U87-MG. CPT-11 similarly inhibited both U87AR and U87-MG proliferation (data not shown).

\section{U87AR SCID Mouse Subcutaneous Model}

After the implantation of $1 \times 10^{5}$ U87AR cells in the flank of 6-week-old male SCID mice (Japan Clea, Japan), U87AR tumor tissue fragments were removed and then reimplanted into another SCID mouse flank. Harvested tumor fragments $1 \mathrm{~mm}^{3}$ in size were simultaneously implanted into the flank of another SCID mouse. When the resulting tumors were palpable, the mice were allocated into each of the treatment groups. In the first set of studies, CPT-11 was administered to mice by conventional schedule on days 11-15 and 18-22 via intraperitoneal (i.p.) injection at 10 (low dose) and 40 (high dose) $\mathrm{mg} / \mathrm{kg}$ in $10 \%$ dimethylsulfoxide (DMSO) in $0.9 \%$ saline. The mice were divided into three groups (6 per group), given: (a) CPT-11 low dose; (b) CPT-11 high dose; (c) saline. Body weight and xenograft tumor dimensions were recorded every each day. In the second set of studies, CPT-11 was administered to the mice by metronomic schedule on days 1 to 21 daily via i.p. injection at 1 (low dose) and 4 (high dose) $\mathrm{mg} / \mathrm{kg}$. The mice were divided into three groups (8 per group), and were treated as follows: (a) metronomic-CPT-11 low dose; (b) metronomic-CPT-11 high dose; (c) saline. 
Body weight and xenograft tumor dimensions were recorded on each day. In the second experiment, 21 days after the implant, the tumor tissues were removed. In order to evaluate the hypoxic area in tumor sections, pimonidazole hydrochloride (Hypoxyprobe-1, Chemicon Temecula, CA) was administered at $120 \mathrm{mg} / \mathrm{kg}$ just prior to sacrifice. A portion of the tissues was immediately fixed in 10\% phosphate buffered formalin for 48 hours, paraffin embedded, and used for routine pathological diagnosis and immunohistochemistry. Other portions of the tissues were immediately frozen in liquid nitrogen and stored at $-70^{\circ} \mathrm{C}$. In the third set of studies, half of the animals treated by the metronomic schedule resumed the treatment after 7 days cessation of treatment; the second cycle of metronomic administration occurred daily on days 29 to 50 via i.p. injection of CPT-11. The xenograft tumor dimensions were recorded every day. The protocols were in adherence with the institutional guidelines for animal welfare and experimental conduct. CPT-11 was provided by Daiichi Pharmaceutical Company (Tokyo).

\section{Antibodies and immunohistochemistry}

The Dako LSAB Kit for mouse and rabbit primary antibody (DAKO, Glostrup, Denmark) was used [9]. Tissue sections were deparaffined and incubated with 10\% normal goat serum in PBS for 20 min. The sections were then incubated with a polyclonal anti-VEGF antibody, A-20 (Santa Cruz Biotech. Inc., CA) at a dilution of 1:100 (1 $\mu \mathrm{g} / \mathrm{ml} \mathrm{IgG),} \mathrm{a} \mathrm{monoclonal} \mathrm{MIB-1} \mathrm{antibody} \mathrm{(Immunotech)} \mathrm{and}$ anti-HIF-1 $\alpha$ antibody (Chemicon) at a dilution of 1:100 in PBS overnight at $4{ }^{\circ} \mathrm{C}$, and a monoclonal anti-mouse CD31 antibody (BD Pharmingen) at a dilution of 1:50 (10 $\mu \mathrm{g} / \mathrm{ml})$ and anti-pimonidazole antibody (Chemicon) at a dilution of 1:20 in PBS for 60 min at room temperature. Chromatographically purified mouse IgG and rabbit IgG (DAKO) at the same IgG concentration were used as negative controls. Sections were incubated with biotin-conjugated goat anti-mouse or anti-rabbit immunoglobulin for $10 \mathrm{~min}$, followed by washing in PBS for 10 min. The sections were 
then incubated with peroxidase-conjugated streptavidin solution for 5 min, followed by washing in PBS for 5 min. Sections were then stained with freshly prepared aminoethylcarbazole solution for 10 min, followed by washing for $5 \mathrm{~min}$ in tap water. The sections were then counterstained with hematoxylin and mounted with aqueous mounting media. The intracellular VEGF immunostaining was assessed for tumor cells using a semiquantitative scale (-, not detected; + moderate; ++. strong). Nuclei positive for MIB-1 were determined by counting at least 1000 tumor cells at homogenously stained area.

\section{Tumor vascular density}

Vascular density was scored using the vasoproliferative component of the microscopic angiogenesis grading system (MAGS) that has been used to quantify angiogenesis in a variety of tumors [10]. The number of vessels at $200 \mathrm{x}$ field $\left(0.31 \mathrm{~mm}^{2}\right)$ was measured in microvessel "hot spots" (i.e., microscopic areas containing the most dense collections of microvessels, identified initially under low power magnification) with the use of an Olympus microscope, AHBT3 (Olympus, Tokyo, Japan) on CD34-stained tissue sections. Vascular density was defined by averaging the number of vessels in the three most vascularised areas.

\section{Measurement of VEGF and HIF-1 $\alpha$ levels in tumor extracts}

Tumor extracts were prepared by homogenizing the tumors in a buffer [10]. VEGF levels were measured in tumor extract supernatants by Quantikine ${ }^{\mathrm{TM}}$ Human VEGF Immunoassay (R\&D systems, Minneapolis, MN). VEGF levels were normalized to total extract protein concentration as measured by DC protein assay and expressed as pg VEGF / mg total extract protein.

Total RNA from frozen tumor samples was collected using the RNeasy Mini Kit (Qiagen, Maryland, MD). Total RNA of $1 \mu \mathrm{g} / \mu$ l or less was used to perform RT-PCR using the GeneAmp RNA PCR kit 
(Applied Biosystems, Foster, CA). The RT-PCR conditions were as follows: 30 sec at $94^{\circ} \mathrm{C}, 30$ sec at $55^{\circ} \mathrm{C}, 30$ sec at $72^{\circ} \mathrm{C}$. To visualize mRNA for human VEGF, HIF- $1 \alpha$ and $\beta$-actin, RT-PCR was performed and the PCR products were visualized on agarose gels. The mRNA expression was then quantitated by densitometry. The VEGF primers consisted of the reverse primer (5'-CCTGGTGAGAGATCTGGTTC-3') and the forward primer (5'-TCGGGCCTCCGAAACCATGA-3') [11]. The HIF-1 $\alpha$ primers included the reverse primer (5'-CCCTGCAGTAGGTTTCTGCT-3') and the forward primer (5’-CTCAAAGTCGGACAGCCTCA-3’) [12].

\section{Statistical analyses}

Vascular density, MIB-1 positivities, tumor volumes, VEGF concentration and densitometric measurements are expressed as the mean \pm SD. Statistically significant differences between the groups were determined using one-way analysis of variance and Tukey’s test. All p-values are two-sided; values were considered statistically significant for $\mathrm{p}<0.05$.

\section{Results}

\section{CPT-11 (conventional treatment) inhibits U87AR glioma growth but with systemic toxicity}

CPT11 at low and high doses of conventional treatment significantly inhibited U87AR subcutaneous glioma growth more than 15 days after the tumor implantation (Figure 1A). The median survival time for each treatment was 7.5 weeks (control), 10.6 weeks (CPT11 low dose), and 11.5 weeks (CPT11 high dose). The effect against growth inhibition was very similar between the low and high doses of CPT11 treatments. However, the body weights of the mice treated with CPT11 were significantly lower 18 days after treatment compared to control mice, suggesting that conventional CPT11 treatment has systemic side effects even at a low dose of CPT11. 


\section{CPT-11 (metronomic treatment) inhibits U87AR glioma growth without systemic toxicity}

Metronomic scheduling of CPT-11 inhibited U87AR glioma growth in a dose-dependent manner (Figure 1B). The total dose of CPT-11 administered was $21 \mathrm{mg} / \mathrm{kg}$ and $84 \mathrm{mg} / \mathrm{kg}$ with the low dose and high dose metronomic schedules, respectively, i.e., one by five dose with the conventional schedule. CPT-11 treatment significantly prolonged the survival of glioma bearing mice (data not shown). The body weights of the mice treated with CPT-11 by the metronomic schedule were very similar to those of control mice, suggesting that metronomic CPT-11 treatment exhibited no systemic side effects.

\section{CPT-11 (metronomic schedule) inhibits U87AR angiogenesis and hypoxia}

Metronomic CPT-11 treatment significantly decreased HIF-1 $\alpha$ mRNA expression (Figure 2). VEGF165 mRNA expression was relatively low compared to controls, but was not significantly different. The U87AR proliferation rate was not different between the controls and the CPT-11 treatment groups (Figure 3A). However, the VEGF protein level was reduced in a dose-dependent manner following metronomic CPT-11 treatment (Figure 3B). Tumor angiogenesis was evaluated by vessel number and vessel area in the tissue sections. Metronomic CPT-11 treatment significantly decreased the vessel number and area (Figure 4).

Finally, HIF-1 $\alpha$ expression and the hypoxic area were evaluated by immunohistochemistry. In the control groups, HIF-1 $\alpha$ expression was observed strongly in the tumor cells around the site of necrosis. Metronomic CPT-11 treatment resulted in reduced necrosis and decreased HIF-1 $\alpha$ expression (Figure 5 A, B, C). The hypoxic areas in tissue sections, which were positive for pimonidazole, were strongly observed around the necrosis in the control group. However, the pimonidazole positive area was decreased in the metronomic CPT-11 treatment groups, at both low and high doses (Figure 5 D, E, F).

CPT-11 (metronomic schedule) inhibition is cytostatic and exhibits resistance 
Re-challenge of metronomic CPT-11 treatment occurred 7 days after the discontinuation of treatment. The tumor started to grow rapidly after the discontinuation of the treatment. The inhibitory effect on tumor growth was minimized by re-challenge metronomic treatment (Figure 6).

\section{Discussion}

We have previously demonstrated that SN-38, an active metabolite of CPT-11, selectively inhibited endothelial cell proliferation and significantly decreased both HIF-1 $\alpha$ and VEGF expression in glioma cells in a dose- and time-dependent manner [4]. The study clearly showed CPT-11 exhibited a direct anti-angiogenic effect on endothelial cells and indirectly on glioma cells via down-regulation of HIF1 $\alpha$ and VEGF. In this study, we demonstrated the effect of metronomic treatment with CPT-11 on glioma growth and angiogenesis. The most striking advantage of metronomic CPT-11 treatment compared to conventional high dose intermittent usage of CPT-11 is that it exhibits no systemic toxicity, such as loss of body weight. Another striking effect was inhibition of glioma angiogenesis through down-regulation of HIF-1 $\alpha$ and VEGF, resulting in decreased vessel densities and areas in the treated groups. However, the limited effect of the re-challenge treatment suggests resistance against the angiosuppression for solid tumors, including gliomas. Furthermore, CPT-11 exhibited a dramatic growth inhibitory effect for the ACNU-resistant glioma clone. Because ACNU, as well as temozolomide, is commonly used in Japan as an alkylating agent for malignant gliomas [13 - 15], the finding that CPT-11 is effective for ACNU-resistant clone is clinically useful concerning the subsequent use of chemotherapy for recurrent cases.

\section{Antiangiogenic activity of metronomic CPT-11 treatment}

Most anticancer drugs cause DNA damage and inhibit tumor cell proliferation. They are usually administered at high doses to kill as many tumor cells as possible. However, standard 
chemotherapeutic drugs, such as vincristine bleomycin, adriamycin, etoposide, 5-fluoruracil, carboplatin, paclitaxel, and cyclophosphamide, can target angiogenesis when the dose and frequency of administration are optimized. Among these chemotherapeutic agents, CPT-11 was more potent in inhibiting endothelial cell tube formation in vitro [4]. Therefore, we selected CPT-11 as a candidate metronomic agent for gliomas.

The antiangiogenic properties of the camptothecins; 9-AC, topotecan, gimatecan, and CPT-11 have been demonstrated in both in vitro and in vivo assays [16 - 22]. While the precise mechanism by which camptothecins affect angiogenesis remains unclear, these drugs may be valuable therapeutic agents for the treatment of angiogenic tumors.

Indeed, preclinical studies have indicated the ability of a number of established cytotoxic drugs, such as cyclophosphamide and vinblastine, to strongly inhibit the growth of sensitive and resistant tumors when administered according to an "anti-angiogenic schedule,” i.e., continuous low-dose scheduling [23 - 25], and many antitumor chemotherapeutic agents, including CPT-11, have been tested clinically for their antiangiogenic potential in systemic cancer [26 - 28].

The continuous low-dose scheduling has been described as the most appropriate to exploit the antiangiogenic potential of cytotoxic drugs $[5,29]$. The metronomic chemotherapy has been experimentally [30] and applied clinically for glioblastoma. Tuettenberg et al. [31] demonstrated that metronomic temozolomide in combination with the COX-2 inhibitor rofecoxib was feasible, safe, and maintained a good quality of life in 13 patients with glioblastoma, especially in those tumors that were characterized by a high angiogenic activity. Furthermore, Kong et al.[32] demonstrated that metronomic temozolomide treatment was effective for patients with recurrent temozolomide-refractory glioblastoma. We demonstrated that metronomic CPT-11 treatment decreased VEGF protein expression, which is the most potent and important angiogenic factor of gliomas and brain tumor stem cells [10, 33, 34]. HIF-1 $\alpha$ mRNA expression was also strongly 
inhibited, even with low dose metronomic CPT-11 treatment. In tissue sections, HIF-1 $\alpha$ expression was decreased, and was associated with diminished necrosis and hypoxic areas detected by pimonidazole staining. The tumor cells within these hypoxic areas are likely important targets because they are resistant to chemotherapy and radiation therapy. Anti-angiogenic treatment, such as metronomic CPT-11 treatment may overcome this problem due to reduction of the hypoxic area. Metronomic CPT-11 treatment decreased the expression of VEGF protein. One of the mechanisms of CPT-11 inhibition of VEGF expression is suggested to be down-regulation of HIF-1 $\alpha$ mRNA expression, i.e., directly upstream of the VEGF pathway [35]. Metronomic CPT-11 treatment decreased expression of VEGF protein, but not VEGF mRNA, in tumor tissues. The recently identified HIF-independent regulation of VEGF by the transcriptional coactivator PGC-1 $\alpha$ may be related to the down regulation of VEGF protein [36]. One of the important mechanisms of anti-tumoral effect of anti-angiogenesis agents is normalization of tumor vasculature, resulting decrease of necrosis and hypoxic area in the tumor [37]. By contrast, overdose of anti-angiogenic agents could result excessive vascular regression associated with increased necrosis and hypoxic area. The therapeutic window of anti-angiogenic agents including CPT-11 is narrow and the administration schedule and the dose of anti-angiogenic agents is very important.

The recent combination therapy with CPT-11 and the angiogenesis inhibitor, TNP470 and thrombospondin-1 shows promise in future developments for the treatment of malignant gliomas as an alternative angiosuppressive treatment [38]. Moreover, dramatic recent advances in the treatment for malignant gliomas with bevacizumab (VEGF neutralizing antibody) combined with CPT-11 treatment[3] have suggested the usefulness of CPT-11 as an anti-angiogenic, cytostatic agent, independent of its cytotoxic anti-tumor effect. Taken together, these results raise the possibility of the novel clinical application of CPT-11 to target hypoxia-inducible factor and VEGF.

\section{Resistance to anti-angiogenesis treatment.}


In our study, the growth inhibitory effect of re-challenged metronomic CPT-11 treatment was limited. The lack of the effectiveness on the re-growing phase is similar to a previous study [39]. There are three reasons to explain this finding: 1) the metronomic treatment is not effective for relatively large tumors, as demonstrated with other antiangiogenesis strategies, 2) the resistance to metronomic treatment appeared with the first treatment, 3) the targeted tumor endothelial cells acquired resistance to CPT-11. The timing of the anti-angiogenic treatment is important. Several clinical studies with metronomic chemotherapy have not been effective for recurrent glioblastomas. Metronomic chemotherapy with methotrexate and cyclophosphamide was ineffective in relapsed, heavily-pretreated glioblastoma [40]. Although there were some responders, the oral metronomic regimens with four drugs, etoposide, cyclophosphamide, thalidomide and celecoxib did not significantly improve the overall survival in the heavily-pretreated group of malignant glioma patients who were generally ineligible for conventional protocols [41]. While metronomic chemotherapy may not be useful in patients with advanced disease, further studies using more potent angiogenic agents in patients with less advanced disease may be warranted. The mechanisms of resistance include revascularization as a consequences of upregulation of alternative pro-angiogenic signals; protection of the tumor vasculature either by recruiting pro-angiogenic inflammatory cells or by increasing protective coverage by pericytes; accentuated invasiveness of tumor cells into local tissues to co-opt the normal vasculature [42, 43]. Tumor endothelial cells are genetically distinct from normal endothelial cells. Tumor endothelial cell clones can acquire resistance to the chemotherapeutic used. To overcome resistance to antiangiogenesis treatment, the HIF regulatory network holds promise as a target, as with metronomic CPT-11 treatment, given its global effects on angiogenesis, invasion and stress-adaptive cell physiology.

In summary, metronomic CPT-11 treatment inhibited human glioma growth in vivo even in the ACNU-resistant clone. Metronomic CPT-11 treatment demonstrated an anti-angiogenic effect, 
inhibition of HIF-1 $\alpha$ and VEGF expression and decreased area of the hypoxic lesion. Clinically, CPT-11 may be a useful chemotherapeutic agent especially for ACNU-treated, recurrent malignant gliomas, in part through its angiosuppressive effect. In combination with strategies that exhibit resistance to antiangiogenic treatment, metronomic CPT-11 treatment presents an exciting future opportunity for improving and sustaining the benefits of malignant glioma therapy.

Acknowledgements We gratefully acknowledge Yoshiko Tsukada and Makiko Miyakawa for their excellent technical assistance. This study was supported by a Grant-in-Aid for Scientific Research from the Japan Society for the Promotion of Science and by a grant provided by the Tsukuba Advanced Research Alliance, Japan Brain Foundation, The Japanese Foundation for research and promotion of endoscopy, and Japanese Foundation for Multidisciplinary Treatment of Cancer. Animal experiments were carried out in a humane manner after receiving approval from the Institutional Animal Experimental Committee of the University of Tsukuba and in accordance with the University’s Regulation for Animal Experiments. 


\section{References}

1. Buckner JC, Reid JM, Wright K, Kaufmann SH, Erlichman C, Ames M, Cha S, O’Fallon JR, Schaaf LJ, Miller LL (2003) Irinotecan in the treatment of glioma patients. Current and future studies of the north central cancer treatment group. Cancer 97(9 suppl): 2352-2358

2. Vredenburgh JJ, Desjardins A, Reardon DA, Friedman HS (2009) Experience with irinotecan for the treatment of malignant glioma. Neuro-Oncol 11: 80-91

3. Vredenburgh JJ, Desjardins A, Herndon II JE, Marcello J, Reardon DA, Quinn JA, Rich JN, Sathornsumetee S, Gururangan S, Sampson J, Wagner M, Bailey L, Bigner DD, Friedman AH, Friedman HS (2007) Bevacizumab plus irinotecan in recurrent glioblastoma multiforme. J Clin Oncol 25: 4722-4729

4. Kamiyama H, Takano S, Tsuboi K, Matsumura A (2005) Anti-angiogenic effects of SN38 (active metabolite of Irinotecan): Inhibition of hypoxia-inducible factor 1 (HIF-1 $\alpha$ ) / vascular endothelial growth factor (VEGF) expression of Glioma and growth of endothelial cells. J Cancer Res Clin Oncol 131: 205-213

5. Hanahan D, Beregers G, Bergsland E (2000) Less is more, regularly: metronomic dosing of cytotoxic drugs can target tumor angiogenesis in mice. J Clin Invest 105: 1045-1047

6. Takano S, Tsuboi K, Matsumura A, Tomono Y, Mistui Y, Nose T (2000) Expression of the angiogenic factor thymidine phosphorylase in human astrocytic tumors. J Cancer Res Clin Oncol 126: 145-152

7. Mineura K, Yanagisawa T, Watanabe K, Kowada M, Yasui N (1996) Human brain tumor O6-methylguanine-DNA methyltransferase mRNA and its significance as an indicator of selective chloroethylnitrosourea chemotherapy. Int J Cancer 69: 420-425

8. Ng SY, Gunning P, Eddy R, Ponte P, Leavitt J, Shows T, Kedes L (1985) Evolution of the functional human beta-actin gene and its multi-pseudogene family: conservation of noncoding 
regions and chromosomal dispersion of pseudogenes. Mol Cell Biol 5: 2720-2732

9. Takano S, Tsuboi K, Matsumura A, Nose T (2003) Anti-vascular endothelial growth factor antibody and nimustine as combined therapy: effects on tumor growth and angiogenesis in human glioblastoma xenografts. Neuro-Oncol 5: 1-7

10. Takano S, Yoshii Y, Kondo S, Maruno T, Shirai S, Nose T (1996) Concentration of vascular endothelial growth factor in the serum and tumor tissue of brain tumor patients. Cancer Res 56: 2185-2190

11. Weindel K, Marme D, Weich HA (1992) AIDS-associated kaposi's sarcoma cells in culture express vascular endothelial growth factor. Biochem Biophys Res Commun 183: 1167-1174

12. Nakayama K, Kanzaki S, Hata K, Katabuchi H, Okamura H, Miyazaki K, Fukumoto M, Takebayashi Y (2002) Hypoxia-inducible factor 1 alpha(HIF-1 $\alpha$ ) gene expression in human ovarian carcinoma. Cancer Lett 176 :215-223

13. Nagane M, Nozue K, Shimizu S, Waha A, Miyazaki H, Kurita H, Homori M, Fujioka Y, Shiokawa Y (2009) Prolonged and severe thrombocytopenia with pancytopenia induced by radiation-combined temozolomide therapy in a patient with newly diagnosed glioblastomaanalysis of O6-methylguanine-DNA methyltransferase status. J Neurooncol 92: 227-32

14. Takakura K, Abe H, Tanaka R, Kitamura K, Miwa T, Takeuchi K, Yamamoto S, Kageyama N, Handa H, Mogami H, Nishimoto A, Uozumi T, Matsutani M, Nomura K (1986) Effects of ACNU and radiotherapy on malignant glioma. J Neurosurg 64: 53-57

15. Yoshida J, Kajita Y, Wakabayashi T (1994) Long-term follow-up results of 175 patients with malignant glioma: importance of radical tumor resection and postoperative adjuvant therapy with interferon, ACNU and radiation. Acta Neurochir (Wien) 127: 55-57

16. Clements MK, Jones CB, Cumming M, Daoud SS (1999) Antiangiogenic potential of camptothecin and topotecan. Cancer Chemother Pharmacol 44: 411-416 
17. McCrudden KW, Yokoi A, Thosani A, Soffer SZ, Kim ES, Huang J, Manley C, O’Toole K, Yamashiro DJ, Kandel JJ, Middlesworth W (2002) Topotecan is anti-angiogenic in experimental hepatoblastoma. J Pediatr Surg 37: 857-861

18. Nakashio A, Fujita N, Tsuruo T (2002) Topotecan inhibits VEGF- and bFGF-induced vascular endothelial cell migration via downregulation of the PI3K-Akt signaling pathway. Int J Cancer 98: $36-41$

19. O’Leary JJ, Shapiro RL, Ren CJ, Chuang N, Cohen HW, Potmesil M (1999) Antiangiogenic effects of camptothecin analogues 9-amino-20(S)-camptothecin, topotecan, and CPT-11 studied in the mouse cornea model. Clin Cancer Res 5: 181-187

20. Petrangolini G, Pratesi G, De Cesare M, Supino R, Pisano C, Marcellini M, Giordano V, Laccabue D, Lanzi C, Zunino F (2003) Antiangiogenic effects of the novel camptothecin ST1481 (Gimatecan) in human tumor xenografts. Mol Cancer Res 1: 863-870

21. Soffer SZ, Kim E, Moore JT, Huang J, Yokoi A, Manley C, O’'Toole K, Middleswoth W, Stolar C, Yamashiro D, Kandel J (2001) Novel use of an established agent: topotecan is anti-angiogenic in experimental Wilms tumor. J Pediatr Surg 36: 1781-1784

22. Xiao D, Tan W, Li M, Ding J (2001) Antiangiogenic potential of 10-hydroxycamptothecin. Life Sci 69: $1619-1628$

23. Browder T, Butterfield CE, Kraling BM, Shi B, Marshall B, O’Reilly MS, Folkman J (2000) Antiangiogenic scheduling of chemotherapy improves efficacy against experimental drug-resistant cancer. Cancer Res 60: 1878-1886

24. Klement G, Baruchel S, Rak J, Man S, Clark K, Hicklin DJ, Bohlem P, Kerbel RS (2000) Continuous low-dose therapy with vinblastin and VEGF receptor-2 antibody induces sustained tumor regression without overt toxicity. J Clin Invest 105: R15-R24

25. Man S, Bocci G, Francia Gm Green Sk, Jothy S, Hanahan D, Bohlen P, Hicklin DJ, Bergeres G, 
Kerbel RS (2002) Antitumor effects in mice of low-dose (metronomic) cyclophosphamide administered continuously through the drinking water. Cancer Res 62: 2731-2735

26. Bocci G, Falcone A, Fioravanti A, Orlandi P, Di Paolo A, Fanelli G, Viacava P, Naccarato AG, Kerbel RS, Danesi R, Del Tacca M, Allegrini G (2008) Antiangiogenic and anticolorectal cancer effects of metronomic irinotecan chemotherapy alone and in combination with semaxinib. Br J Cancer 98: 1619-1629

27. Ogata Y, Mori S, Ishibashi N, Akagi Y, Ushijima M, Murakami H, Fukushima T, Shirouzu K (2007) Metronomic chemotherapy using weekly low-dosage CPT-11 and UFT as postoperative adjuvant therapy in colorectal cancer at high risk to recurrence. J Exp Clin Cancer Res 26: $475-482$

28. Shirner M (2000) Antiangiogenic chemotherapeutic agents. Cancer Metastasis Rev 19: 67-73

29. Gately S, Kerbel R (2001) Antiangiogenic scheduling of lower dose cancer chemotherapy. Cancer J 7: 427-436

30. Bello L, Carrabba G, Giussani C, Lucini V, Cerutti F, Scaglione F, Landre J, Pluderi M, Tomei G, Villani R, Carroll RS, Black PM, Bikfalvi A (2001) Low-dose chemotherapy combined with an antiangiogenic drug reduces human Glioma growth in vivo. Cancer Res 61: 7501-7506

31. Tuettenberg J, Grobholz R, Korn T, Wenz F, Erber R, Vajkozy P (2005) Continuous low-dose chemotherapy plus inhibition of cyclooxygenase-2 as an antiangiogenic therapy of glioblastoma multiforme. J Cancer Res Clin Oncol 131: 31-40

32. Kong DS, Lee JI, Kim WS, Son MJ, Lim DH, Kim ST, Park K, Kim JH, Eoh W, Nam DH (2006) A pilot study of metronomic temozolomide treatment in patients with recurrent temozolomide-refractory glioblastoma. Oncol Rep 16: 1117-1121

33. Folkins C, Man S, Xu P, Shaked Y, Hicklin DJ, Kerbel RS (2007) Anticancer therapies combining antiangiogenic and tumor cell cytotoxic effects reduce the tumor stem-like cell 
fraction in glioma xenograft tumors. Cancer Res 67: 3560-3564

34. Gilbertson RJ, Rich JN (2007) Making a tumour's bed: glioblastoma stem cells and the vascular niche. Nat Rev Cancer 7: 733-736

35. Rapisarda A, Uranchimeg B, Sordet O, Pommier Y, Shoemaker RH, Melillo G (2004) Topoisomerase I-mediated inhibition of hypoxia-inducible factor 1: mechanism and therapeutic implications. Cancer Res 64: 1475-1482

36. Arany Z, Foo SY, Ma Y, Ruas JL, Bommi-Reddy A, Girnum G, Cooper M, Laznik D, Chinsomboon J, Rangwala SM, Baek KH, Rosenzweig A, Spiegelman BM (2008) HIF-independent regulation of VEGF and angiogenesis by the transcriptional coactivator PGC-1 $\alpha$. Nature 451: 1008-1012

37. Jain RK (2005) Normalization of tumor vasculature: an emerging concept in antiangiogenic therapy. Science 307: 58-62

38. Allegrini G, Goulette FA, Darnowski JW, Calabresi P (2004) Thrombospondin-1 plus irinotecan: a novel antiangiogenic-chemotherapeutic combination that inhibits the growth of advanced human colon tumor xenografts in mice. Cancer Chemother Pharmacol 53: 261-266

39. Kaneko S, Ishibashi M, Kaneko M (2008) Vascular endothelial growth factor expression is closely related to irinotecan-mediated inhibition of tumor growth and angiogenesis in neuroblastoma xenografts. Cancer Sci 99: 1209-1217

40. Herrlinger U, Rieger J, Steinbach JP, Nagele T, Dichgans J, Weller M (2005) UKT-04 trial of continuous metronomic low-dose chemotherapy with methotreaxate and cyclophophamide for recurrent glioblastoma. J Neuro-oncol 71: 295-299, 2005.

41. Kesari S, Schiff D, Doherty L, Gigas DC, Batchelor TT, Muzikansky A, O’Neill A, Drappatz J, Chen-Plotkin AS, Ramakrishna N, Weiss SE, Levy B, Bradshaw J, Kracher J, Laforme A, Black PM, Folkman J, Kieran M, Wen PY (2007) Phase II study of metronomic chemotherapy for 
recurrent malignant gliomas in adults. Neuro-Oncol 9: 354-363.

42. Bergers G, Hanahan D (2008) Modes of resistance to antiangiogenic therapy. Nature Reviews Cancer 8: 592-603

43. Jain RK, Duda DG, Clark JW, Loeffler JS (2006) Lessons from phase III clinical trials on anti-VEGF therapy for cancer. Nat Clin Pract Oncol 3: 24-40 


\section{Figure legends}

Figure 1

The effect of CPT-11 on the growth of subcutaneous xenografts of U87 MG human malignant glioma cells in SCID mice. Mice were implanted in the flank with a tumor fragment. When the resulting tumors were palpable, mice were allocated into treatment groups of five animals each. A: Conventional treatment. CPT-11 (low: $10 \mathrm{mg} / \mathrm{kg}$, high $40 \mathrm{mg} / \mathrm{kg}$ ) was administered to the mice on days 11-15 and 18-22 via intraperitoneal injection. B: Metronomic treatment. CPT-11 (low: 1mg/kg, high: $4 \mathrm{mg} / \mathrm{kg}$ ) was administered to mice on days 1-21 via intraperitoneal injection. Body weight and xenografts tumor dimensions were recorded twice weekly. The results are presented as the means \pm SD. $* \mathrm{p}<0.01$

Figure 2

HIF-1 $\alpha$ and VEGF mRNA expression of U87 subcutaneous tumor tissue treated by metronomic schedule. A. HIF-1 $\alpha$ expression was strongly observed in 4 of 8 control tumor tissues. HIF-1 $\alpha$ expression were weak in tumor tissues with low and high dose metronomic treatment. B. Semiquantitation of mRNA expression using fluoroimager. HIF-1 $\alpha$ / actin ratio were significantly lower in low and high dose metronomic treated group compared to control group. ${ }^{*} \mathrm{p}<0.01$

Figure 3

MIB-1 positivities and VEGF concentration measured by ELISA. A: MIB-1 positivities were similar between control and the CPT-11 treatment group. B: VEGF concentration in tumor tissues were significantly lower in low and high dose metronomic CPT-11 compared to control. * $\mathrm{p}<0.05$, * $\mathrm{p}<0.001$ 
Figure 4

Angiosuppressive effect of CPT-11. Immunohistochemical detection of tumor vessels stained by CD34. A: control, B: high dose metronomic treatment. Metronomic CPT-11 treatment significantly decreased the vessel number (C) and area (D).

Figure 5

Immunohistochemical detection of HIF-1 $\alpha$ expression (A, B, C) and hypoxic area (D, E, F). In the control groups, HIF-1 $\alpha$ expression was strongly observed in the tumor cells around the necrosis (A). Metronomic CPT-11 treatment resulted in a decrease of the necrotic area and decreased expression of HIF-1 $\alpha$ (B; metronomic low dose, C; metronomic high dose). Hypoxic areas in tissue sections that were positive for pimonidazole were strongly observed around the necrosis in the control group (D). However, the pimonidazole-positive area was decreased in the metronomic CPT-11 treatment groups at both low (E) and high (F) dose.

Figure 6. CPT-11 metronomic treatment was cytostatic. The tumor growth was inhibited by first metronomic treatment (cycle 1). The tumor started to grow rapidly during the discontinuation of the treatment (rest). The inhibitory effect on tumor growth was minimized by re-challenge metronomic treatment (cycle 2). 
Figure 1

\section{Conventional Treatment} CPT11 day11-15, day 18-22
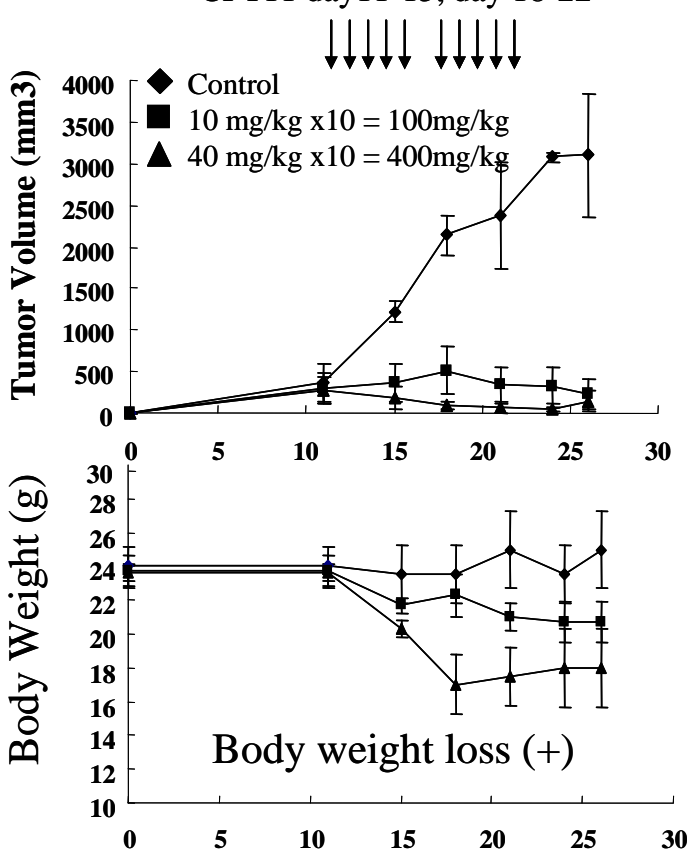

A

Days after implantation
Metronomic Treatment CPT11 everyday day 1-21

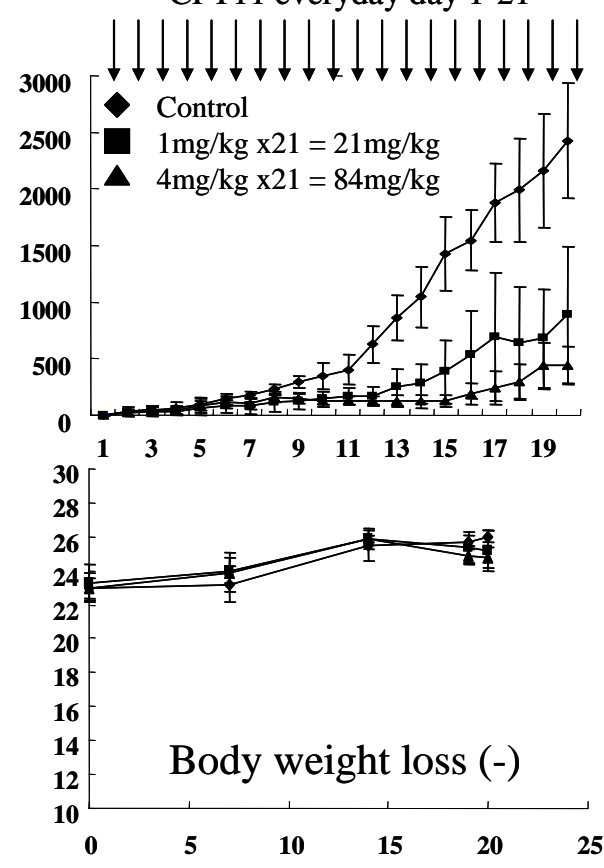

B

Days after implantation 
Figure 2

A

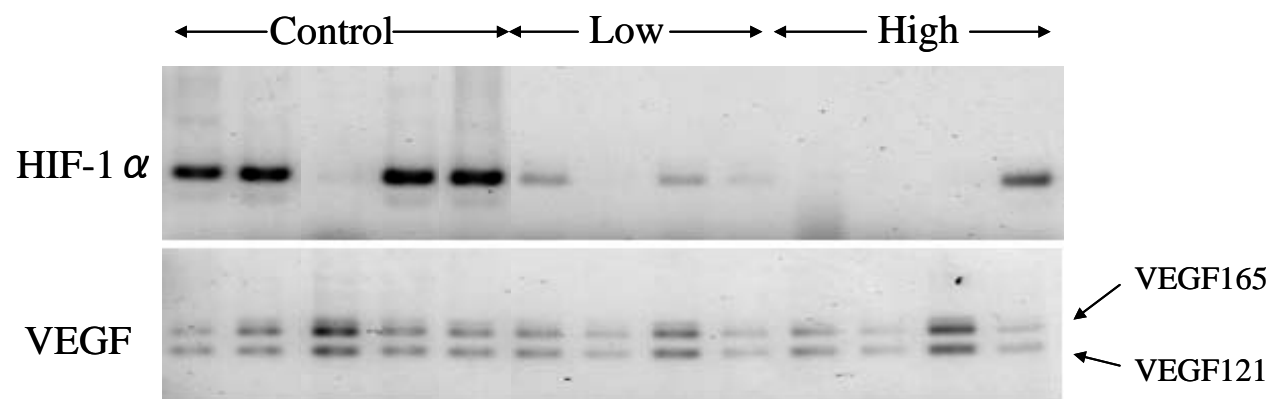

$\beta$ actin

B
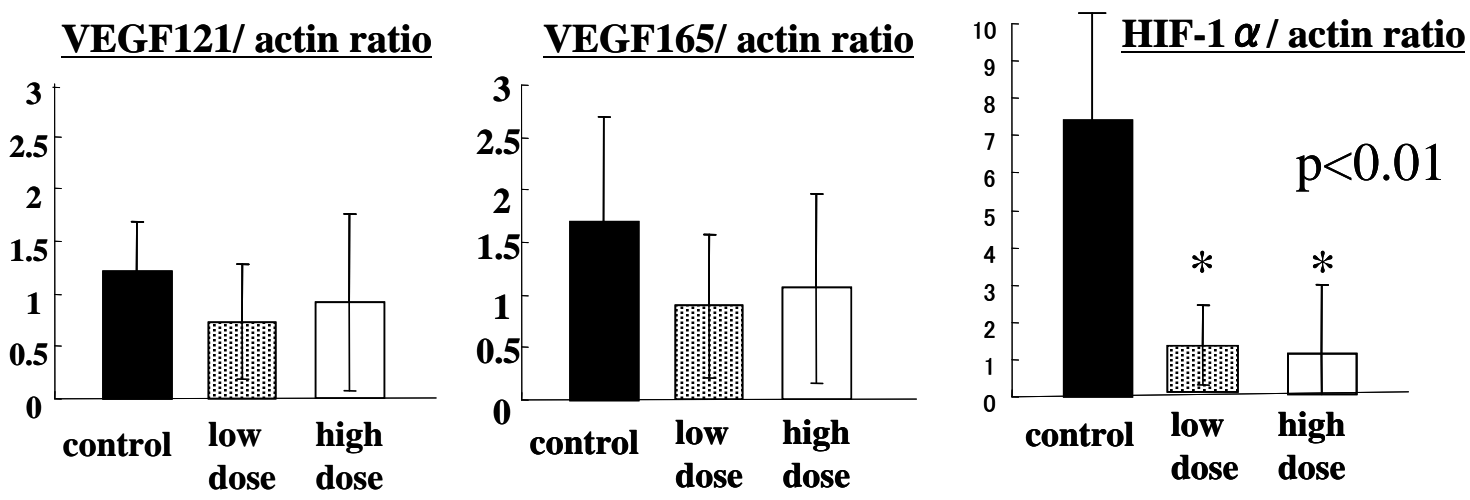
Figure 3
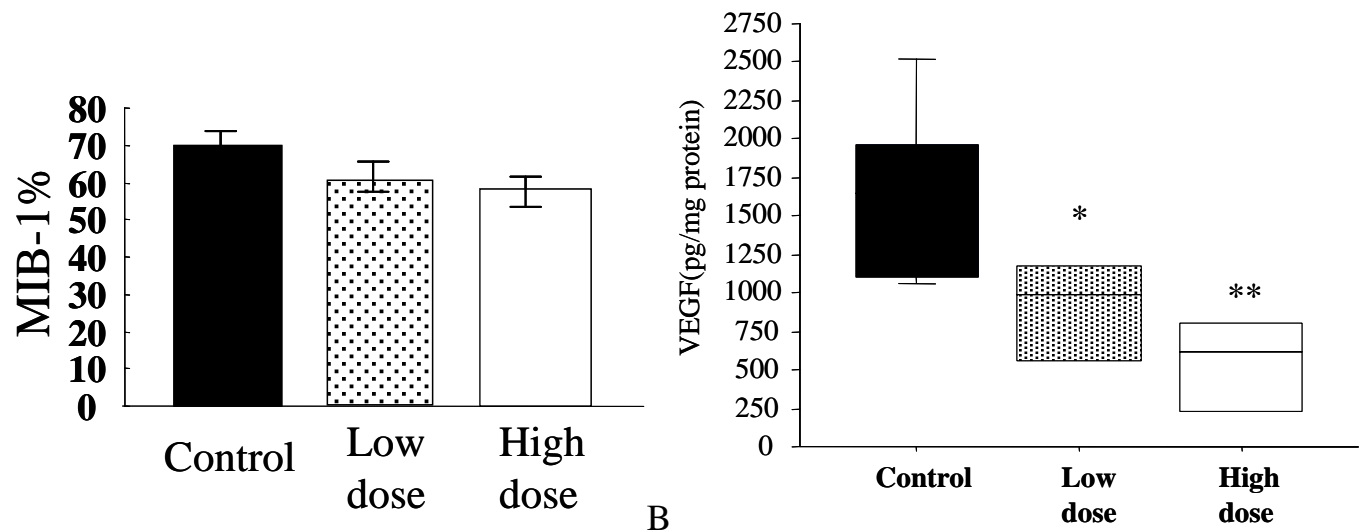
Figure 4
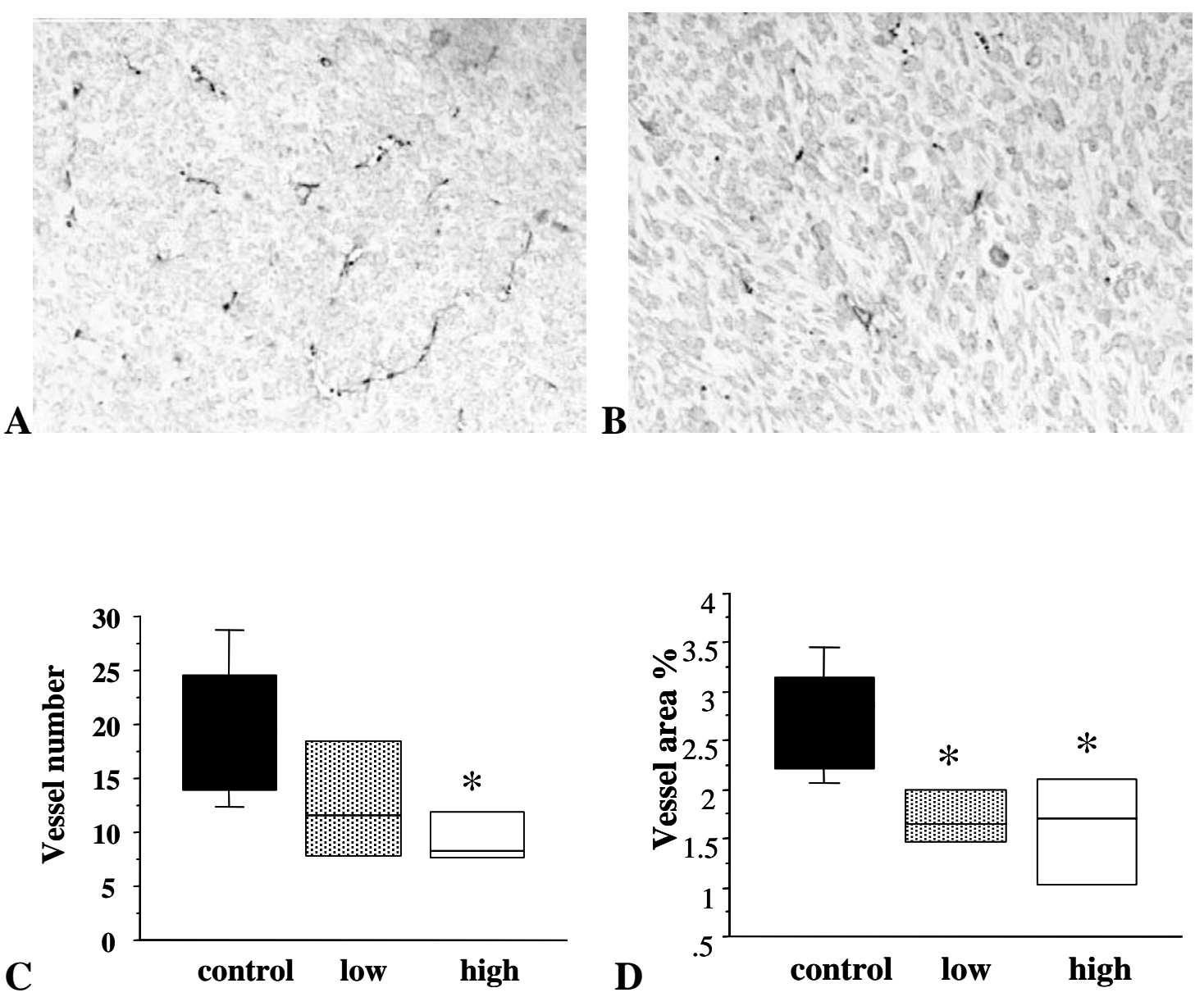
Figure 5

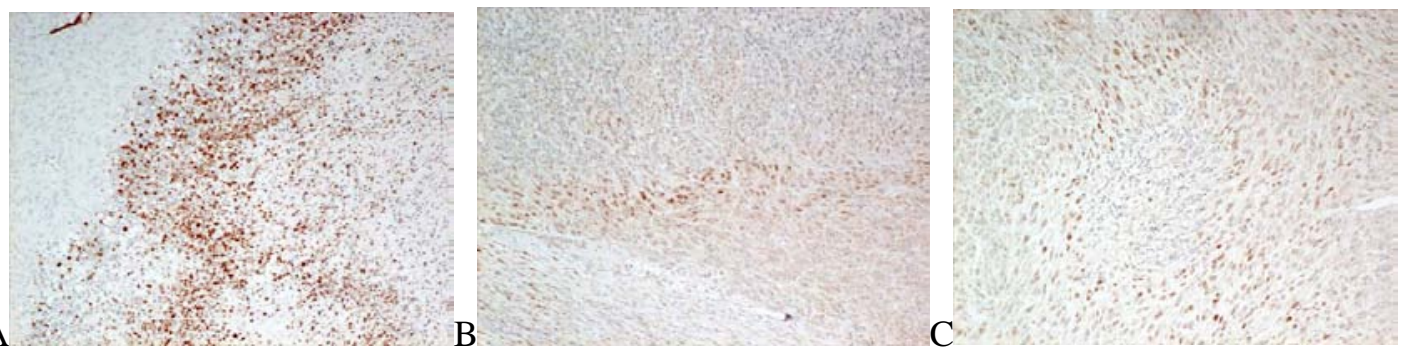

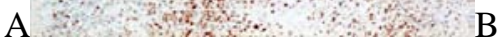

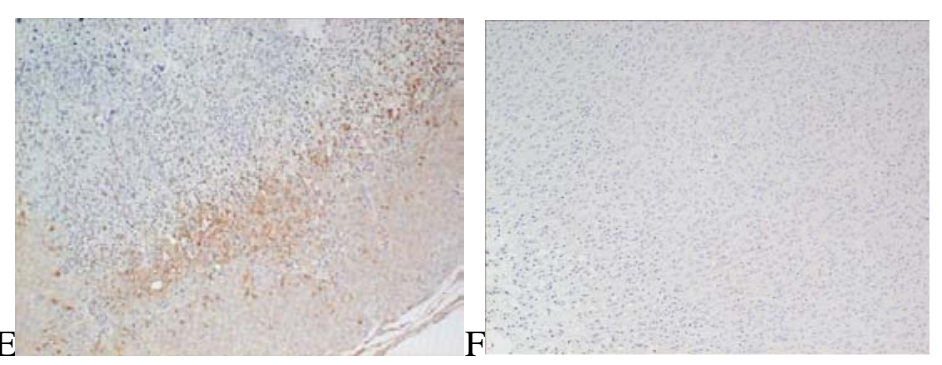

D

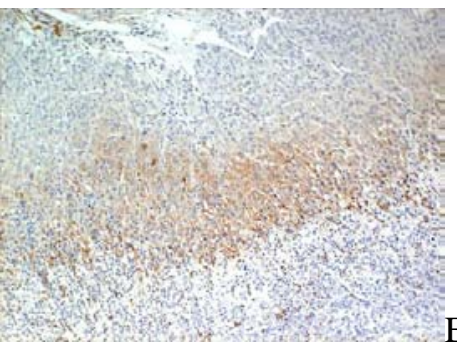


Figure 6

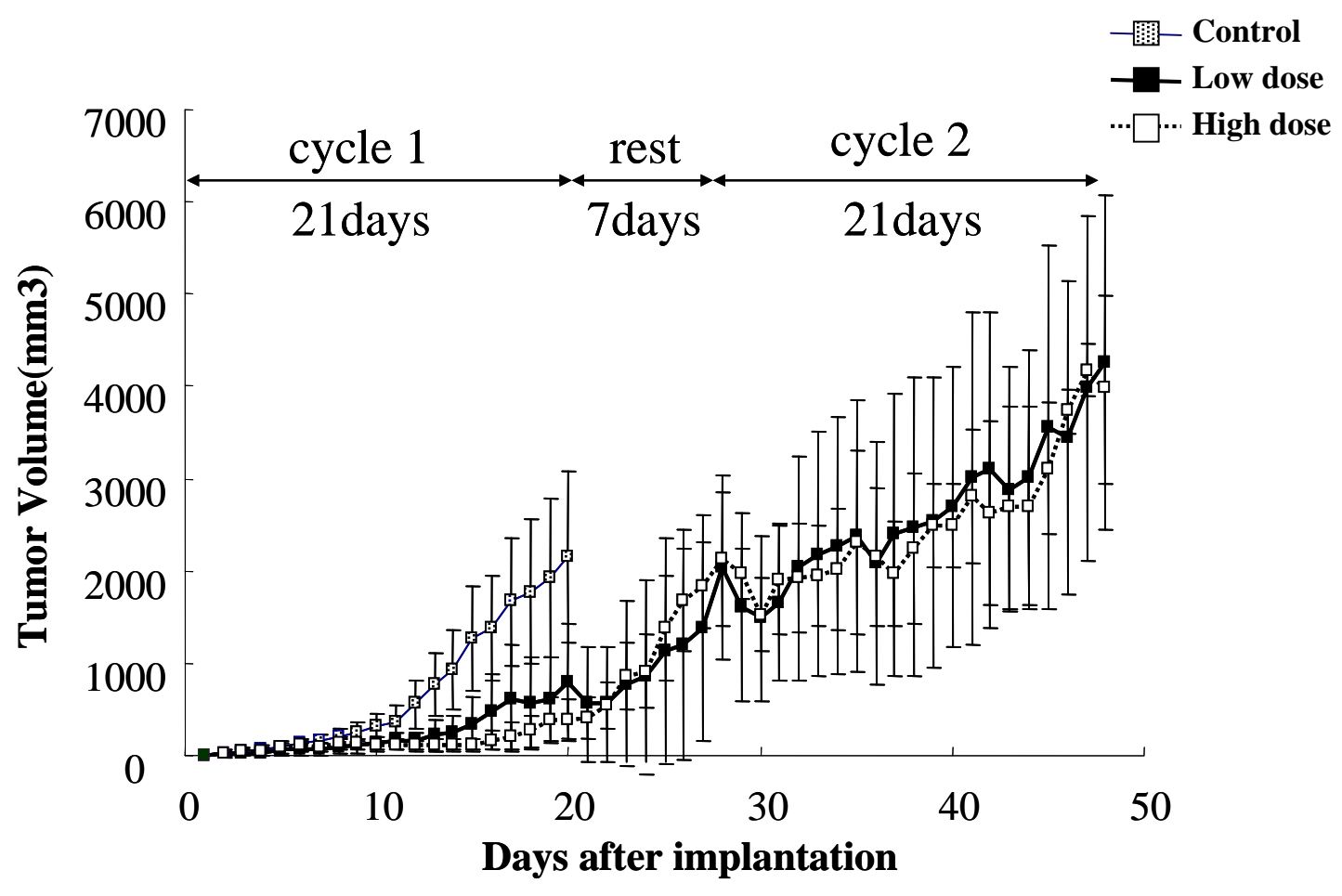

